\title{
Circulating microRNA profile predicts disease progression in patients receiving second-line treatment of lapatinib and capecitabine for metastatic pancreatic cancer
}

\author{
XUEFEI TIAN $^{1 *}$, NARAYAN SHIVAPURKAR ${ }^{1 *}$, ZHENG WU $^{1}$, JIMMY J. HWANG ${ }^{1}$, MICHAEL J. PISHVAIAN ${ }^{1}$, \\ LOUIS M. WEINER ${ }^{1}$, LISA LEY ${ }^{1}$, DAN ZHOU ${ }^{2}$, XIULING ZHI ${ }^{1}$, ANTON WELLSTEIN ${ }^{1}$, \\ JOHN L. MARSHALL ${ }^{1}$ and AIWU RUTH HE ${ }^{1}$
}

${ }^{1}$ Division of Hematology and Oncology, Lombardi Comprehensive Cancer Center;

${ }^{2}$ Department of Pathology, Georgetown University, Washington, DC 20007, USA

Received February 14, 2015; Accepted September 30, 2015

DOI: $10.3892 / \mathrm{ol} .2016 .4101$

\begin{abstract}
Patients exhibiting pancreatic cancer possess poor rates of survival. Therefore, the identification of a biomarker that can be measured non-invasively and be used to predict patient outcomes is required for the successful treatment of pancreatic cancer. The present study evaluated serum microRNA (miRNA/miR) profiles in patients exhibiting pancreatic cancer, who were treated with lapatinib and capecitabine in a phase II trial. Serum samples were collected for the measurement of a panel of miRNAs (miR-21, miR-210, miR-221 and miR-7) associated with the epidermal growth factor receptor (EGFR)1 and human epidermal growth factor receptor (HER)2 pathways. Preclinically, human pancreatic cancer PANC-1, MIA PaCa-2 and BXCP-3 cell lines were utilized for miRNA and drug resistance studies. In total, 6/17 patients treated experienced disease progression following 2 cycles of treatment [non-responders (NRS)], while another $6 / 17$ patients exhibited a stable disease state and received $>4$ cycles of treatment [responders (RS); range, 4-22 cycles]. Five patients withdrew from the study due to severe toxicity or mortality. The mean overall survival time was 6.5 vs. 10.4 months for NRS and RS, respectively. Significant upregulation of serum miRNAs at earlier time points (3-6 weeks) was observed in NRS. miRNA levels increased with cancer progression, and lapatinib and 5-fluorouracil (5-FU; the active form of capecitabine) treatment increased the miRNA levels (specifically miR-210 and miR-221) in the treatment-resistant
\end{abstract}

Correspondence to: Dr Aiwu Ruth $\mathrm{He}$ and Dr Narayan Shivapurkar, Division of Hematology and Oncology, Lombardi Comprehensive Cancer Center, Georgetown University, 3800 Reservoir Road NW, Washington, DC 20007, USA

E-mail: arh29@georgetown.edu

E-mail:nms35@georgetown.edu

*Contributed equally

Key words: pancreatic cancer, lapatinib, predict, biomarker, microRNA-221 pancreatic cancer PANC-1 and MIA PaCa-2 cell lines. However, lapatinib and 5-FU treatment did not increase the miRNA levels in the treatment-sensitive BXPC-3 cell line. Inhibition of miR-221 increased the sensitivity of the PANC-1 cells to treatment. In conclusion, an increase in specific serum miRNAs was associated with resistance to lapatinib and capecitabine treatment. Additional investigation is required with regard to the application of the miRNA panel investigated in the present study as a potential predictor of patient responses to anti-EGFR/HER2 treatment.

\section{Introduction}

More than 37,000 individuals develop pancreatic adenocarcinoma annually in the United States, and the majority of these succumb to the disease due to its aggressive characteristics and the fact that a large number of patients present with relatively advanced disease. The 5-year survival rate of patients with pancreatic adenocarcinoma is $<5 \%$, therefore, improved medical intervention is required $(1,2)$. Surgical resection offers the only option for a cure, however, resectable disease is exhibited by only $15-20 \%$ of patients at the time of the initial diagnosis; the majority of patients present with locally advanced or metastatic cancer $(1,2)$. Effective systemic therapy is key for prolonging the survival of patients exhibiting advanced pancreatic cancer.

Increased expression of the first member of the ErbB family to be identified, epidermal growth factor receptor (EGFR), and its ligand, epidermal growth factor (EGF), have been detected in $40-60 \%$ of human pancreatic cancer cases. The co-expression of EGFR and its ligand has been identified as a predictor of a poor prognosis (3). The targeting of EGFR with the tyrosine kinase inhibitor erlotinib demonstrated a marked survival benefit when combined with gemcitabine treatment, compared with gemcitabine treatment alone (4). Human epidermal growth factor receptor 2 (HER2; ErbB2)-targeted therapy has been demonstrated to significantly improve clinical outcomes in breast and gastric cancer $(5,6)$. A total of $20 \%$ of pancreatic cancers demonstrate HER2 overexpression. When monoclonal antibodies were utilized to target EGFR and HER2 synergistically in xenograft models, augmented inhibition of tumor 
progression was observed, compared with single monoclonal antibody treatment $(\mathrm{P}=0.006)$ or no treatment $(\mathrm{P}=0.0004)$, and a number of complete remissions were evident (7).

Lapatinib is a tyrosine kinase inhibitor, which binds EGFR and HER2 (8). In an international phase III trial of HER2-positive breast cancers, treatment with lapatinib and capecitabine [pro-drug of 5-fluorouracil (FU)] significantly improved the time to progression, compared with capecitabine treatment alone (9). Therefore, in the present study, a single-arm phase II study was conducted, in order to evaluate the combination of lapatinib and capecitabine for the second-line treatment of metastatic pancreatic cancer.

Biomarkers that predict responses to anticancer therapy have been sought in order to identify effective treatments and understand the mechanisms of resistance. MicroRNAs (miRNAs/miRs) are small ( 22-nt), non-coding RNAs that possess a significant role in the control of a wide range of cellular processes, including apoptosis, cell proliferation, the regulation of embryonic stem cell development and cancer cell invasion (10). A number of studies have revealed that miRNA signatures may be used for distinguishing between various cancers, and additionally for defining the prognosis $(11,12)$. A previous study revealed that, unlike a number of other biomarker types, circulating miRNAs are stable, making them reliable and robust biomarkers for cancer (13). Specific miRNAs (including miR-21, miR-221, miR-210 and miR-7) have been implicated as downstream effectors of the EGFR and HER2 signaling pathways (12-17). The aim of the present study was to investigate whether the levels of the aforementioned miRNA(s) in blood are able to predict the clinical outcome for patients receiving lapatinib and capecitabine treatment, and to evaluate how this group of miRNAs contribute to the resistance to lapatinib and capecitabine treatment in patients.

\section{Materials and methods}

Patients and clinical study design. A total of 17 patients with metastatic, gemcitabine-refractory pancreatic cancer were recruited at the Lombardi Comphrensive Cancer Center (Washington, USA) between March 2009 and September 2013. The patient cohort included 13 males and 4 females, with a mean age of 61 years (range, 52-73 years). All patients received continuous treatment with lapatinib $(1,250 \mathrm{mg}$, daily) and capecitabine $\left(1,000 \mathrm{mg} / \mathrm{m}^{2}\right.$, twice daily) on days $1-14$ of each 21-day cycle until disease progression occurred or the patients were unable to tolerate chemotherapy. The primary endpoint was median overall survival (OS). Serum samples were collected at baseline (before treatment) and every 3 weeks during the study for miRNA analysis. This study was approved by the Institutional Review Board of Georgetown University (Washington, USA) (IRB\#CR00000441/ 2008-437) and written informed consent was obtained from all patients.

Cell culture and pharmacological agents. Human pancreatic cancer PANC-1, MIA PaCa-2 and BXCP-3 cell lines were purchased from the American Type Culture Collection (Manassas, VA, USA), and maintained in RPMI 1640 medium supplemented with $10 \%$ fetal bovine serum (FBS) (Gibco; Thermo Fisher Scientific Inc., Waltham, MA, USA). All cells were cultured at $37^{\circ} \mathrm{C}$ in $5 \% \mathrm{CO}_{2}$, with $100 \%$ humidity. The cells were treated with $4 \mu \mathrm{M}$ lapatinib and $16 \mu \mathrm{M} 5-\mathrm{FU}$, or with anti-miRNA oligonucleotides (AMOs) or a vehicle control at various doses at $37^{\circ} \mathrm{C}$, and analyzed following $72 \mathrm{~h}$ of incubation. Lapatinib was purchased from Santa Cruz Biotechnology, Inc. (Dallas, TX, USA) and 5-FU was obtained from Sigma-Aldrich (St. Louis, MO, USA), and 3-(4,5-dimethylthiazol-2-yl)-5-(3-carboxymethoxyphenyl)-2(4-sulfophenyl)-2H-tetrazolium was obtained from Promega Corp. (Madison, WI, USA). The AMOs hsa-miR-221-3p (MIMAT0000278) and hsa-miR-210 (MI0000286), and the negative control (scrambled sequence) were purchased from Thermo Fisher Scientific Inc.

Cell survival assay. The cells were seeded into 96-well plates at a density of $1 \times 10^{4}$ cells/well in $50 \mu 1$ RPMI 1640 medium with 10\% FBS (Gibco; Thermo Fisher Scientific Inc.), and incubated for $24 \mathrm{~h}$ at $37^{\circ} \mathrm{C}$. Subsequently, the cells were exposed to lapatinib and/or 5-FU at increasing concentrations $(0.25,1,4$ and $16 \mu \mathrm{M})$ in an additional $50 \mu 1$ medium. Cell survival was assayed following $72 \mathrm{~h}$ of incubation using a CellTiter $96^{\circledR}$ Aqueous One Solution Cell Proliferation Assay kit (Promega Corp.). Measurements were performed in accordance with the manufacturer's protocols. Assessment of cell survival rate was recorded as the relative colorimetric change measured at $570 \mathrm{~nm}$ using a VICTOR2 Multilabel Counter (PerkinElmer Finland, Turku, Finland).

Transfection with hsa-miR. Transfection of the cells with hsa-miR was performed using Lipofectamine ${ }^{\circledR}$ RNAiMAX reagent (Invitrogen; Thermo Fisher Scientific Inc.) according to the manufacturer's transfection protocol. Briefly, the cells were seeded into 6 -well $\left(2 \times 10^{5}\right.$ cells/well) plates prior to transfection. Following $24 \mathrm{~h}$ of incubation, hsa-miR or scrambled sequence were diluted in serum-free medium, and incubated with Lipofectamine RNAiMAX reagent for $10 \mathrm{~min}$ at room temperature. Complexes were added dropwise onto cells. Cell survival was assayed $72 \mathrm{~h}$ after transfection. Knockdown of miRNA levels was determined using quantitative polymerase chain reaction (qPCR). Briefly, total RNA enriched in miRNA was prepared from cell pellets $\left(\sim 10^{6}\right.$ cells $)$ using the miRNAeasy Mini Kit (Qiagen, Inc., Valencia, CA, USA). miRNA levels were determined following conversion of RNA to cDNA using a $\mathrm{RT}^{2}$ miRNA first strand kit (Qiagen, Inc.). cDNA was amplified using the Applied Biosystems 7900HT Fast Real-Time PCR system (Thermo Fisher Scientific Inc.), SYBR qPCR reaction mixture and miRNA specific primers (Qiagen, Inc.). PCR was performed under the following conditions: Initial denaturation at $95^{\circ} \mathrm{C}$ for $10 \mathrm{~min}$, followed by 40 cycles of $95^{\circ} \mathrm{C}$ for $15 \mathrm{sec}, 60^{\circ} \mathrm{C}$ for $30 \mathrm{sec}$ and $72^{\circ} \mathrm{C}$ for $30 \mathrm{sec}(18,19)$. U6 spliceosomal RNA served as an internal control, and data was quantified using the comparative $\mathrm{Cq}$ method (20).

In order to determine the effects of hsa-miR pretreatment on cell sensitivity to lapatinib and 5-FU, the PANC-1 cells were seeded in 100-mm dishes at an initial density of $5 \times 10^{5}$ cells and transfected with hsa-miR or scramble sequence for $24 \mathrm{~h}$. The cells were subsequently collected and transferred to a 96-well plate $\left(1 \times 10^{4}\right.$ cells/well). Lapatinib $(4 \mu \mathrm{M})$ and 5-FU $(16 \mu \mathrm{M})$ were added in a combined concentration following $24 \mathrm{~h}$ of incubation, with 5 replicate plate columns per treatment. 


\begin{tabular}{|c|c|c|c|c|c|c|c|c|c|c|c|c|c|c|c|c|c|c|c|c|}
\hline patient \# & 12 & & 15 & & 6 & 7 & & & 14 & & & 16 & & & & 9 & & & 10 & \\
\hline time (weeks) & 3 & 9 & 3 & 9 & 4 & 6 & 9 & 12 & 3 & 6 & 9 & 3 & 4 & 9 & 12 & 6 & 12 & 15 & 6 & 9 \\
\hline miR-21 & 5.54 & 10.93 & 1 & 2.69 & 1.06 & .7 .692 & -3.846 & 1.22 & -5.263 & & 2.9 & 1.04 & -1.22 & -3.226 & -1.7857 & -2.5 & -1.667 & -2.5 & -2 & 3.16 \\
\hline miR-210 & 2 & 2.66 & 3.25 & 1.47 & -1.786 & -2.381 & -2.326 & -2.5 & -1.316 & 1.77 & 1.47 & -1.087 & 1.2 & -1.449 & -3.5714 & -1.124 & 1.18 & 1.01 & -2.5 & 2.06 \\
\hline miR-221 & 21.11 & 32.67 & 4.5 & 1.88 & -2.439 & -4.348 & -4.762 & -4 & -1.563 & 1.06 & -1.724 & 1.01 & -2.083 & -1.923 & -2.9412 & -1.408 & -1.22 & -1.25 & -2.439 & \\
\hline miR-7 & 3.25 & 1.42 & -1.58 & 1.47 & 4.26 & -1.923 & -1.111 & -2.703 & -1.754 & 1.18 & 1.37 & -3.226 & -2.632 & -5 & .5 & 1.85 & 2.38 & 1.96 & -1.538 & 3.46 \\
\hline
\end{tabular}

fold up / down time $=$ relative to start of treatment

\begin{tabular}{|c|c|c|c|c|c|c|c|c|c|c|}
\hline patient \# & 12 & 15 & 6 & 7 & 14 & & 16 & & 9 & 10 \\
\hline time (weeks) & 3 & 3 & 4 & 6 & 3 & 6 & 3 & 4 & 6 & 6 \\
\hline miR-21 & 5.54 & 1 & 1.06 & -7.69 & -5.26 & -10 & 1.04 & -1.22 & -2.5 & -2 \\
\hline miR-210 & 2 & 3.25 & -1.79 & -2.38 & -1.32 & 1.77 & -1.09 & 1.2 & -1.12 & -2 \\
\hline $\mathrm{miF}$ & 21.11 & 4.5 & -2.44 & -4.35 & -1.56 & 1.06 & 1.01 & -2.08 & -1.41 & -2.4 \\
\hline $\mathrm{miF}$ & 3.25 & -1.6 & 4.26 & -1.92 & -1.75 & 1.18 & -3.23 & -2.63 & 1.85 & -1.5 \\
\hline
\end{tabular}

fold up / down time $=$ relative to treatment start

C

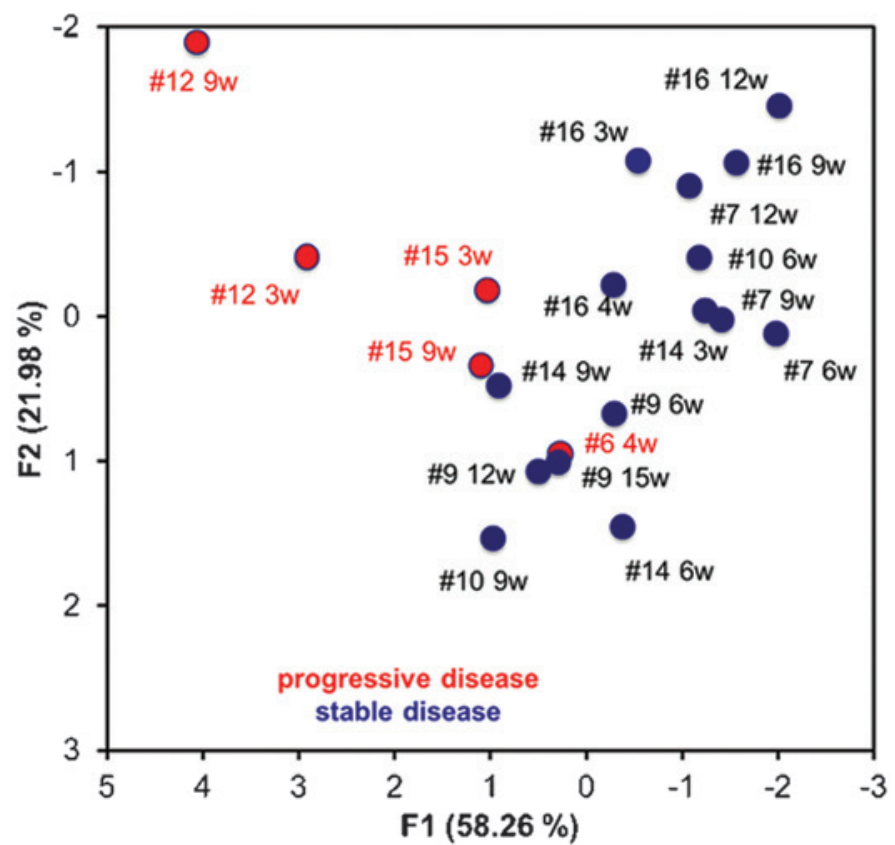

Figure 1. Heat maps demonstrating the differential expression of circulating miRNAs between responders and non-responders. The miRNA expression analysis was performed for miR-21, miR-210, mir-221 and miR-7 using quantitative polymerase chain reaction. (A) miRNA expression data at all time points expressed as PCA. (B) Representation of miRNA expression data at early time point only. Data from progressive and stable groups are represented by red and blue symbols, respectively. (C) Principal component analysis with measurements of circulating miRNA at all time points. Data from progressive and stable groups are represented by red and blue symbols, respectively. miRNA/miR, microRNA; PCA, principal component analysis.

Following $72 \mathrm{~h}$ of treatment, cell survival was determined using the CellTiter $96^{\circledR}$ Aqueous One Solution Cell Proliferation Assay kit (Promega Corp.), as described above.

Reverse transcription-qPCR of miRNA. Total RNA was isolated from the serum of patients or cells using the QIAzol ${ }^{\mathrm{TM}}$ reagent (Qiagen, Inc.) as previously described $(18,19)$. The miRNA expression analysis was performed using qPCR analysis as previously reported $(18,19)$. Briefly, serum samples were mixed at a ratio of 1:10 with QIAzol ${ }^{\mathrm{TM}}$ lysis reagent and vortexed for $1 \mathrm{~min}$ using a mini vortexer (Thermo Fisher Scientific, Inc). Cell pellets $\left(\sim 10^{6}\right.$ cells $)$ were mixed with $1 \mathrm{ml}$ QIAzol $^{\text {TM }}$ reagent (Qiagen, Inc.). The lysates were extracted using $\mathrm{CHCl}_{3}$ and the aqueous phase was further processed, removing phenol and other contaminants, to obtain total RNA enriched in miRNA using the miRNAeasy Mini Kit (Qiagen, Inc.). miRNA levels were determined following conversion of RNA to cDNA using the $\mathrm{RT}^{2}$ miRNA first strand kit (Qiagen, Inc.) followed by amplification of cDNA in the Applied Biosystems 7900HT Fast Real-Time PCR system (Thermo Fisher Scientific, Inc.) using SYBR qPCR reaction mixture and miRNA specific primers (Qiagen, Inc.). Amplification of cDNA was performed under the following conditions: Initial denaturation at $95^{\circ} \mathrm{C}$ for $10 \mathrm{~min}$, followed by 40 cycles of $95^{\circ} \mathrm{C}$ for $15 \mathrm{sec}, 60^{\circ} \mathrm{C}$ for $30 \mathrm{sec}$ and $72^{\circ} \mathrm{C}$ for $30 \mathrm{sec}(18,19)$. U6 spliceosomal RNA served as an internal control, and data was quantified using the comparative $\mathrm{Cq}$ method (20). 

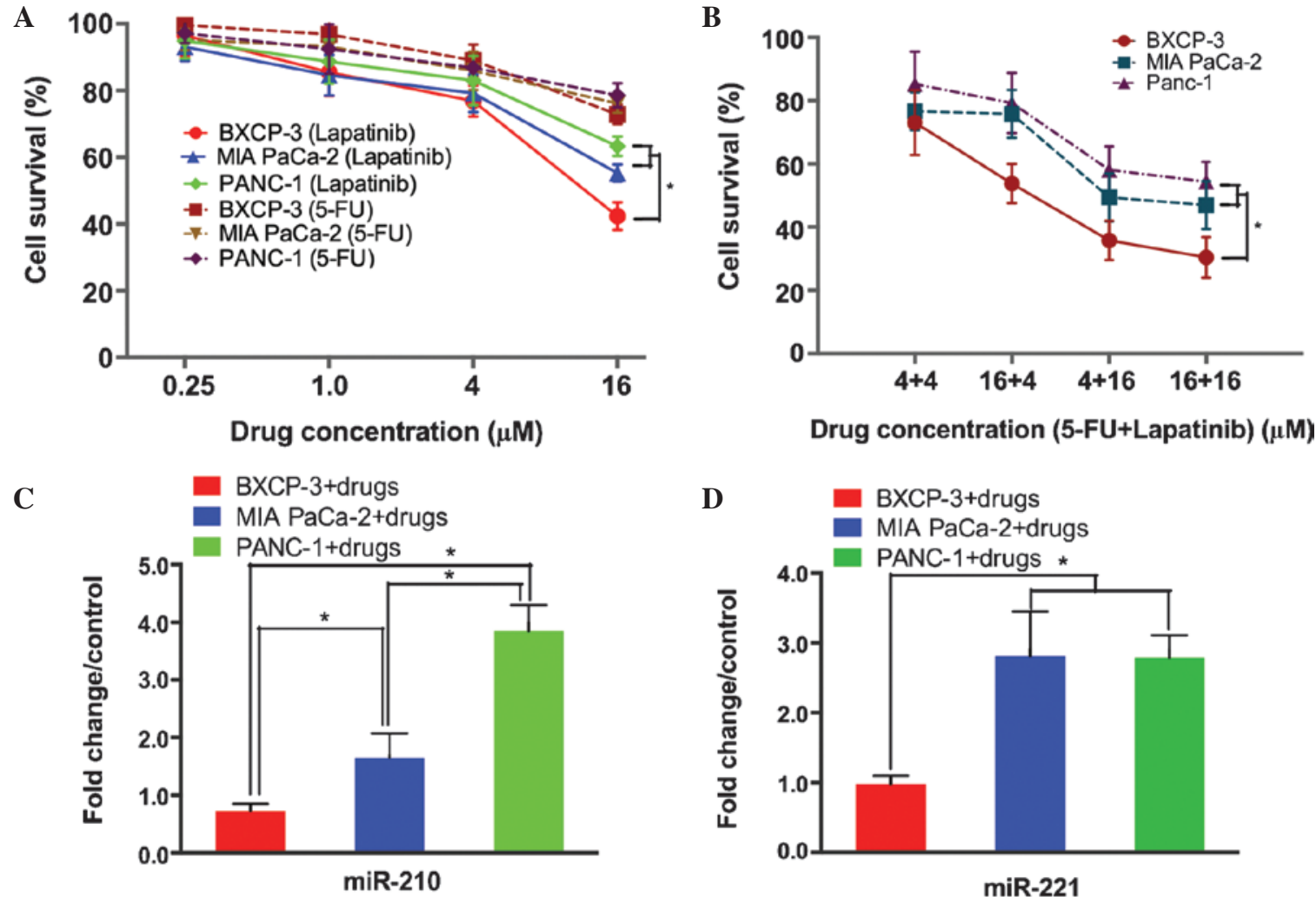

Figure 2. Sensitivities of the BXCP-3, MIA PaCa-2 and PANC-1 human pancreatic cancer cell lines to lapatinib and 5-FU as (A) single agents or (B) in combination. The change in the (C) miR-210 and (D) miR-221 levels in human pancreatic cancer cells treated with a lapatinib + 5-FU combination (lapatinib, $4 \mu \mathrm{M} ; 5-\mathrm{FU}, 16 \mu \mathrm{M})$. *P<0.05. 5-FU, 5-fluorouracil; miR, microRNA.

A

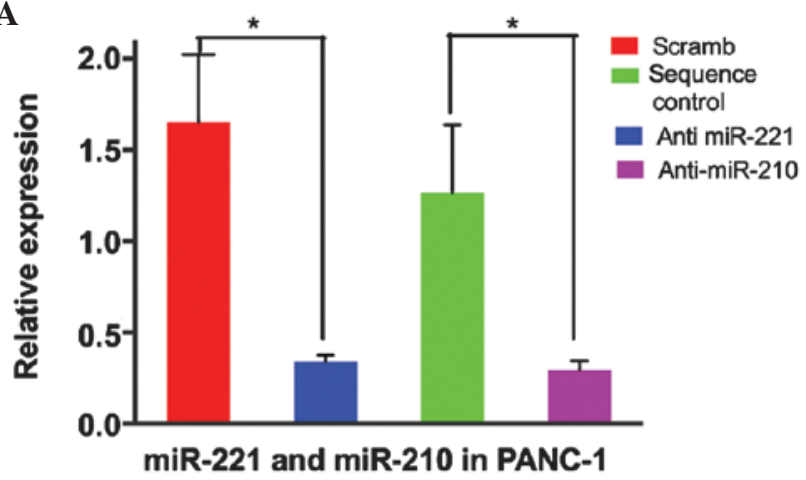

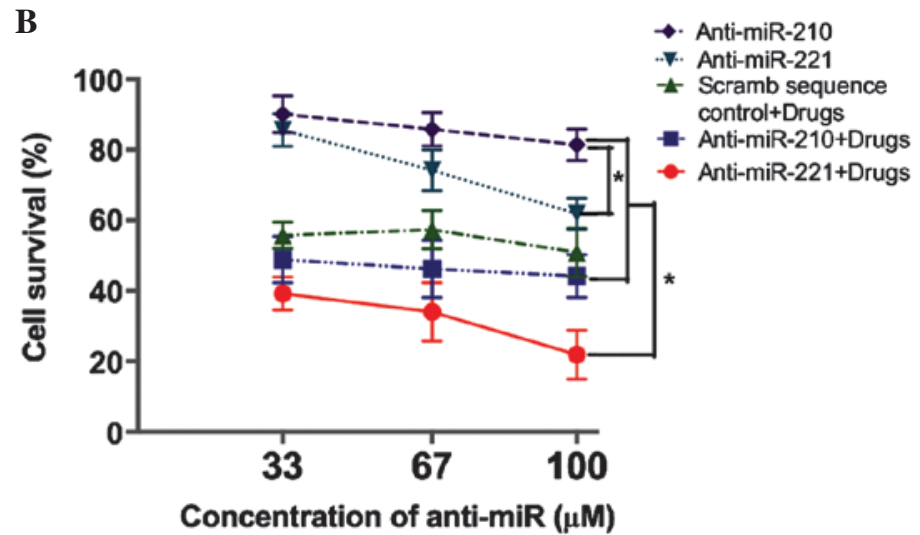

Figure 3. Cell transfection. (A) Levels of miR-221 and miR-210 in PANC-1 cells following transfection with scramble sequence control or anti-miR-221/210 $(100 \mathrm{nM})$. (B) Viability of pancreatic cancer cells when the levels of miR-221 or miR-220 were suppressed alone, or in combination with chemotherapy treatment. Drug treatment, anti-miR transfection, survival assay and miRNA expression analysis were performed as described in the Materials and methods. Results are presented as the mean \pm standard deviation. ${ }^{*} \mathrm{P}<0.05$. miRNA/miR, microRNA.

Statistical analysis. miRNA levels in the cells or patient specimens and survival data were tested by a one-way analysis of variance test using GraphPad Prism Software version 5.0 (GraphPad Software, Inc., La Jolla, CA, USA). Results are presented as the mean \pm standard deviation. OS and progression free survival curves were estimated using the Kaplan-Meier method. OS and progression free survival are presented as the median $\pm 95 \%$ confidence interval. Principal component analysis was used to analyze the association between serum miRNA levels and drug response. $\mathrm{P}<0.05$ was considered to indicate a statistically significant difference.

\section{Results}

Analysis of miRNA levels in patient serum. A total of 17 patients presenting with advanced pancreatic cancer, who demonstrated cancer progression following first-line chemotherapy, were enrolled in an institutional review board (IRB)-approved phase II clinical trial (IRB\# CR00000441/2008-437; Clinical Trials.gov identifier, NCT00881621), and were administered $1,250 \mathrm{mg}$ lapatinib daily and $1,000 \mathrm{mg} / \mathrm{m}^{2}$ capecitabine twice daily, on days 1-14 of a 21-day cycle. A total of 8 patients, including 3 non-responders (NRS; defined as demonstrating 
disease progression following 2 cycles of treatment) and 5 responders ( $\mathrm{RS}$; defined as demonstrating stable disease following 2 cycles of treatment), underwent serial serum sample collection at baseline, and at 3 and 6 weeks. The expression profile of a panel of miRNAs (miR-21, miR-210, miR-221 and miR-7), which are associated with EGFR1 and HER2 signaling pathways, was analyzed for fold-changes in expression (compared with baseline).

Heat chart analysis of the miRNA expression profiles clearly demonstrated varying expression profiles between patient numbers 6, 12 and 15 (NRS) and patient numbers 7, 9, 10, 14 and 16 (RS) (Fig. 1A). Most significantly, heat chart analysis at early time points in treatment predicted the subsequent prognosis of the patients as RS or NRS (Fig. 1B). Principal component analysis of the data clearly separated RS from NRS utilizing all data, or data for only early time points (Fig. 1C).

miR-221 and miR-210 levels increase in chemoresistant pancreatic cancer cells treated with lapatinib and 5-FU in vitro, and suppression of miR-221 increases the sensitivity of cancer cells to treatment. In order to confirm the observation that the panel of miRNAs identified as being significant for the prediction of patient responses to therapy were indeed associated with prognosis, 3 pancreatic cancer cell lines (PANC-1, MIA PaCa-2 and BXCP-3) with varying levels of sensitivity to lapatinib and 5-FU were selected in order to study the role of miRNA in treatment resistance. The cell viability assay demonstrated that the PANC-1 and MIA PaCa- 2 cells possessed increased resistance to lapatinib alone or in combination with 5-FU treatment, compared with the BXCP-3 cells (Fig. 2A and B). The miRNA analysis revealed significant upregulation of miR-210 in the PANC-1 $(1.65 \pm 0.42$-fold; $\mathrm{P}<0.05)$ and MIA PaCa-2 (3.85 \pm 0.45 -fold; $\mathrm{P}<0.01)$ cells, however, no such upregulation was observed in the $\mathrm{BXCP}-3$ cells $(0.73 \pm 0.12$-fold; BXPC-3 + drug vs. PANC-1 + drug) (Fig. 2C). Following treatment with lapatinib and 5-FU, the levels of miR-221 were observed to be increased in the PANC-1 and MIA PaCa- 2 cells by $2.81 \pm 0.32$-fold and $2.79 \pm 0.32$-fold, respectively $(\mathrm{P}<0.01)$, however, no such increase was observed in the BXCP-3 cells $(0.98 \pm 0.12$ fold; BXPC-3 + drug vs. PANC-1 + drug; $\mathrm{P}=0.0026)$ (Fig. 2D). There were no significant alterations observed in the expression of miR-7 and miR-21 in all 3 pancreatic cancer cell lines investigated (data not shown).

Based on observations from the cell lines and patients, we hypothesized that an increase in miR-221 or miR-210 contributed to the resistance of cancer cells to lapatinib and capecitabine treatment. In order to evaluate the effect of miR-221 or miR-210 inhibition on the response of pancreatic cancer cells to lapatinib and 5-FU treatment, anti-miR-221 or anti-miR-210 were transfected into the PANC-1 cells. This transfection resulted in a 4.9-fold decrease in miR-221 and a 4.2-fold decrease in miR-210 compared with a scramble sequence-transfected group $(\mathrm{P}=0.001$; Fig. $3 \mathrm{~A})$. The cell viability assay demonstrated that anti-miR-221 transfection into the PANC-1 cells induced the sensitivity of the cells to lapatinib and 5-FU treatment in a dose-dependent manner, compared with no change in sensitivity to treatment in the control cells transfected with scramble sequence (scrambled sequence control + drug vs. anti-miR-221 + drug; $\mathrm{P}=0.001$; Fig. 3B). By contrast, decreasing the levels of miR-210 did not alter the sensitivity of the PANC-1 cells to lapatinib and 5-FU treatment (Fig. 3B).

\section{Discussion}

Chemoresistance is a significant cause of treatment failure in pancreatic cancer $(21,22)$. The dual inhibition of EGFR and HER 2 has been proposed as a potential treatment for pancreatic adenocarcinoma based on the observed increased levels of EGFR/HER2 heterodimers present in pancreatic cancer cells (23). The present investigation therefore consisted of a single-arm phase II study to evaluate the combination of lapatinib and capecitabine for the second-line treatment of metastatic pancreatic cancer. Notably, a subset of patients existed (6/17) that responded to lapatinib and capecitabine treatment with a mean overall survival time of 10.4 months (median, 8.3 months). In the search for a biomarker to differentiate patients who responded to lapatinib and capecitabine treatment from patients who were resistant to this treatment, the present study identified that the increase in circulating miRNAs from a targeted panel (associated with EGFR and HER2 signaling pathways) that had been observed to be linked with a poor prognosis and a lack of response to lapatinib and capecitabine treatment. Similar pathway-specific patterns in circulating miRNAs between NRS and RS have been observed in a previous study involving the treatment of colon cancer patients with an antiangiogenic agent (24).

In order to determine whether miRNAs serve purely as a biomarker, or additionally contribute to the resistance of pancreatic cancer cells to lapatinib and capecitabine treatment, the present study performed additional experiments in 3 pancreatic cancer cell lines that possessed various levels of sensitivity to lapatinib and 5-FU (the active form of capecitabine) in vitro. The present study identified that the levels of miR-210 and miR-221 were increased in response to drug treatment in the resistant cells (PANC-1), compared with the levels in sensitive cells (BXCP-3), which was in keeping with results obtained from the patient serum samples of the NRS and RS groups. Unlike miR-210 or miR-221, the expression of miR-7 and miR-21 in the pancreatic cell lines did not alter in the same way as it did in patient serum samples. This may be attributed to the differential response of other cell types (including fibroblasts and lymphocytes) to treatment with anticancer drugs. The potential significance of this response with regard to patient outcomes may not be explained using the present experimental model. The current study subsequently demonstrated that blocking of the increase in miR-221 levels, but not miR-210 levels, sensitized the pancreatic cancer cells to lapatinib and 5-FU treatment. This observation supported the hypothesis that miR-221 may possess a significant role in the chemoresistance to lapatinib treatment. The results of the present study support the idea that miR-221 may have potential as a prognostic marker and potential target for therapeutic interventions in pancreatic cancer $(25,26)$. It is notable to consider the reported ability of certain natural compounds to downregulate miR-221 in pancreatic cancer cells in preclinical studies $(27,28)$. If proven safe to administer to patients, these agents require evaluation for their ability to downregulate miR-221 in clinical studies. 
The present study demonstrated that a subset of pancreatic cancer patients received benefits from lapatinib, a treatment that induces the combined inhibition of the EGFR and HER2 signaling pathways. An increase in miR-221 levels in the blood, detected 3 weeks after the beginning of lapatinib and capecitabine treatment, may predict treatment failure and a lack of clinical benefit in patients exhibiting pancreatic cancer. The results of the present study require the performance of future studies in order to evaluate the role of miR-221 in the prediction of lapatinib treatment failure, as well as the effect of a combined lapatinib and anti-miR-221 agent on the patient response to treatment.

\section{Acknowledgements}

The present study was supported by the American Cancer Society (grant no. 118525-MRSG-10-068-01-TBE), as well as by the Ruesch Center for the Cure of Gastrointestinal Cancer.

\section{References}

1. Jemal A, Siegel R, Xu J and Ward E: Cancer statistics, 2010. CA Cancer J Clin 60: 277-300, 2010

2. Valsecchi ME, Díaz-Cantón E, de la Vega M and Littman SJ: Recent treatment advances and novel therapies in pancreas cancer: A review. J Gastrointest Cancer 45: 190-201, 2014.

3. Vaccaro V, Gelibter A, Bria E, Iapicca P, Cappello P, Di Modugno F, Pino MS, Nuzzo C, Cognetti F, Novelli F, et al: Molecular and genetic bases of pancreatic cancer. Curr Drug Targets 13: 731-743, 2012.

4. Moore MJ, Goldstein D, Hamm J, Figer A, Hecht JR, Gallinger S, Au HJ, Murawa P, Walde D, Wolff RA, et al; National Cancer Institute of Canada Clinical Trials Group: Erlotinib plus gemcitabine compared with gemcitabine alone in patients with advanced pancreatic cancer: A phase III trial of the National Cancer Institute of Canada Clinical Trials Group. J Clin Oncol 25: 1960-1966, 2007.

5. Won E, Janjigian YJ and Ilson DH: HER2 directed therapy for gastric/esophageal cancers. Curr Treat Options Oncol 15: 395-404, 2014.

6. Rimawi MF, Schiff R and Osborne CK: Targeting HER2 for the treatment of breast cancer. Annu Rev Med 66: 111-128, 2015.

7. Larbouret C, Robert B, Navarro-Teulon I, Thèzenas $S$, Ladjemi MZ, Morisseau S, Campigna E, Bibeau F, Mach JP, Pèlegrin A and Azria D: In vivo therapeutic synergism of anti-epidermal growth factor receptor and anti-HER2 monoclonal antibodies against pancreatic carcinomas. Clin Cancer Res 13: 3356-3362, 2007.

8. Xia W, Mullin RJ, Keith BR, Liu LH, Ma H, Rusnak DW, Owens G, Alligood KJ and Spector NL: Anti-tumor activity of GW572016: A dual tyrosine kinase inhibitor blocks EGF activation of EGFR/erbB2 and downstream Erk1/2 and AKT pathways. Oncogene 21: 6255-6263, 2002.

9. Cameron D, Casey M, Press M, Lindquist D, Pienkowski T, Romieu CG, Chan S, Jagiello-Gruszfeld A, Kaufman B, Crown J, et al: A phase III randomized comparison of lapatinib plus capecitabine versus capecitabine alone in women with advanced breast cancer that has progressed on trastuzumab: Updated efficacy and biomarker analyses. Breast Cancer Res Treat 112: 533-543, 2008

10. Bartel DP: MicroRNAs: Genomics, biogenesis, mechanism, and function. Cell 116: 281-297, 2004.

11. Calin GA and Croce CM: MicroRNA signatures in human cancers. Nat Rev Cancer 6: 857-866, 2006.

12. Walther A, Johnstone E, Swanton C, Midgley R, Tomlinson I and Kerr D: Genetic prognostic and predictive markers in colorectal cancer. Nat Rev Cancer 9: 489-499, 2009.
13. Mitchell PS, Parkin RK, Kroh EM, Fritz BR, Wyman SK, Pogosova-Agadjanyan EL, Peterson A, Noteboom J, O'Briant KC, Allen A, et al: Circulating microRNAs as stable blood-based markers for cancer detection. Proc Natl Acad Sci USA 105: 10513-10518, 2008.

14. Drakaki A and Iliopoulos D: MicroRNA-gene signaling pathways in pancreatic cancer. Biomed J 36: 200-208, 2013.

15. Garofalo M, Romano G, Di Leva G, Nuovo G, Jeon YJ, Ngankeu A, Sun J, Lovat F, Alder H, Condorelli G, et al: EGFR and MET receptor tyrosine kinase-altered microRNA expression induces tumorigenesis and gefitinib resistance in lung cancers. Nat Med 18: 74-82, 2012.

16. Seike M, Goto A, Okano T, Bowman ED, Schetter AJ, Horikawa I, Mathe EA, Jen J, Yang P, Sugimura H, et al: MiR-21 is an EGFR-regulated anti-apoptotic factor in lung cancer in never-smokers. Proc Natl Acad Sci USA 106: 12085-12090, 2009.

17. Chou YT, Lin HH, Lien YC, Wang YH, Hong CF, Kao YR, Lin SC, Chang YC, Lin SY, Chen SJ, et al: EGFR promotes lung tumorigenesis by activating miR-7 through a Ras/ERK/Myc pathway that targets the Ets2 transcriptional repressor ERF. Cancer Res 70: 8822-8831, 2010.

18. Larbouret C, Gaborit N, Chardès T, Coelho M, Campigna E, Bascoul-Mollevi C, Mach JP, Azria D, Robert B and Pèlegrin A: In pancreatic carcinoma, dual EGFR/HER2 targeting with cetuximab/trastuzumab is more effective than treatment with trastuzumab/erlotinib or lapatinib alone: Implication of receptors' down-regulation and dimers' disruption. Neoplasia 14: 121-130, 2012.

19. LaConti JJ, Shivapurkar N, Preet A, Deslattes Mays A, Peran I, Kim SE, Marshall JL, Riegel AT and Wellstein A: Tissue and serum microRNAs in the Kras(G12D) transgenic animal model and in patients with pancreatic cancer. PLoS One 6: e20687, 2011.

20. Livak KJ and Schmittgen TD: Analysis of relative gene expression data using real-time quantitative PCR and the 2(-Delta Delta C(T)) Method. Methods 25: 402-408, 2001

21. Shivapurkar N, Weiner LM, Marshall JL, Madhavan S, Deslattes Mays A, Juhl H and Wellstein A: Recurrence of early stage colon cancer predicted by expression pattern of circulating microRNAs. PLoS One 9: e84686, 2014.

22. Andersson R, Aho U, Nilsson BI, Peters GJ, Pastor-Anglada M, Rasch W and Sandvold ML: Gemcitabine chemoresistance in pancreatic cancer: Molecular mechanisms and potential solutions. Scand J Gastroenterol 44: 782-786, 2009.

23. Ghaneh P, Kawesha A, Evans JD and Neoptolemos JP: Molecular prognostic markers in pancreatic cancer. J Hepatobiliary Pancreat Surg 9: 1-11, 2002.

24. Sarkar S, Dubaybo H, Ali S, Goncalves P, Kollepara SL, Sethi S, Philip PA and Li Y: Down-regulation of miR-221 inhibits proliferation of pancreatic cancer cells through up-regulation of PTEN, p27(kip1), p57(kip2), and PUMA. Am J Cancer Res 3: 465-477, 2013.

25. Shivapurkar N, Mikhail S, Navarro R, Bai W, Marshall J, Hwang J, Pishvaian M, Wellstein A and He AR: Decrease in blood miR-296 predicts chemotherapy resistance and poor clinical outcome in patients receiving systemic chemotherapy for metastatic colon cancer. Int J Colorectal Dis 28: 887, 2013.

26. Kawaguchi T, Komatsu S, Ichikawa D, Morimura R, Tsujiura M, Konishi H, Takeshita H, Nagata H, Arita T, Hirajima S, et al: Clinical impact of circulating miR-221 in plasma of patients with pancreatic cancer. Br J Cancer 108: 361-369, 2013.

27. Su A, He S, Tian B, Hu W and Zhang Z: MicroRNA-221 mediates the effects of PDGF-BB on migration, proliferation, and the epithelial-mesenchymal transition in pancreatic cancer cells. PLoS One 8: e71309, 2013.

28. Basu A, Alder H, Khiyami A, Leahy P, Croce CM and Haldar S: MicroRNA-375 and MicroRNA-221: Potential noncoding RNAs associated with antiproliferative activity of benzyl isothiocyanate in pancreatic cancer. Genes Cancer 2: 108-119, 2011. 